\title{
Obstructive sleep apnea is highly prevalent in COVID19 moderate to severe ARDS survivors: Findings of level I Polysomnography in a tertiary care hospital
}

\section{Authors and affiliations:}

Dr Abhishek Goyal MD, DM. Associate Professor, Pulmonary Medicine, AllMS Bhopal

Dr Khushboo Saxena DNB, Pulmonary Medicine, AlIMS Bhopal

Dr Avishek Kar MD, Pulmonary Medicine, AlIMS Bhopal

Dr Alkesh Khurana. MD. Associate Professor, Pulmonary Medicine, AlIMS Bhopal

Dr Parneet Kaur Bhagtana. MBBS.AIIMS Bhopal

Dr Chinta Siva Koti Rupa Sridevi. MBBS.AIIMS Bhopal

Dr Abhijit Pakhare. MD. Associate Professor, CFM, AlIMS Bhopal.

\section{Corresponding Author:}

Dr Abhishek Goyal MD, DM. Associate Professor, Pulmonary Medicine, AlIMS Bhopal, Saket Nagar, Bhopal- 462024, India. Email: abhishek.pulmed@aiimsbhopal.edu.in

Institution: AlIMS Bhopal, India-462024

All authors have seen and approved the manuscript.

No of tables: 2 No of Figure: 1

Abstract Word count: 196

Manuscript word Count: 2287 


\begin{abstract}
-
Study Objectives- Studies have found Obstructive Sleep Apnea (OSA) as a risk factor for increased risk for COVID19 Acute respiratory Distress Syndrome (ARDS); but most of the studies were done in already known patients of OSA. This study was done to find prevalence of OSA in patients with COVID-19 related acute respiratory distress syndrome.
\end{abstract}

\title{
Methodology-
}

A hospital based longitudinal study was conducted among COVID 19 Intensive Care Unit (ICU) survivors. All consecutive COVID19 with moderate to severe ARDS were evaluated for OSA by Level I Polysomnography (PSG) after 4-6 weeks of discharge. Prevalence of OSA and PSG variables \{Total sleep time, Sleep efficiency, sleep stage percentage, Apnea Hypopnea Index (AHI), T90, nadir oxygen\} was estimated.

Results- Out of 103 patients discharged from ICU during study period (October 2020 to 15 December 2020), 67 underwent Level I PSG. Mean Age was $52.6 \pm 10.9$ years and mean Body Mass Index was $27.5 \pm$ $6.2 \mathrm{Kg} / \mathrm{m}^{2}$. Total sleep time was $343.2 \pm 86$ minutes, sleep efficiency was $75.9 \pm 14.2 \%$. OSA $(A H I \geq 5)$ was seen in $65 / 67$ patients and 49 patients had moderate to severe OSA (i.e. $A H I \geq 15$ ).

Conclusion- Moderate-severe OSA was highly prevalent (73\%) in COVID19 moderate to severe ARDS survivors. Role of OSA in pathophysiology of COVID19 ARDS needs further evaluation. 
Highlights

- This study was done to find prevalence of OSA in patients with COVID-19 related Acute respiratory distress syndrome

- Moderate-severe OSA is highly prevalent (73\%) in COVID19 ARDS survivors.

- To the best of our knowledge, it is first study in which level I PSG was done in COVID19 survivors. 


\section{Introduction:}

COVID-19 has been one of the biggest catastrophe in the history of mankind Till date 100 million people have been infected and more than 2 million have died of this infection.

Severity of COVID-19 infection has been attributed to several comorbid conditions like systemic hypertension, diabetes mellitus, coronary artery disease and chronic kidney disease. ${ }^{1}$ In an attempt to decipher the pathophysiology and predisposing conditions, researchers are exploring newer avenues. Published articles have also assessed Obstructive Sleep Apnea(OSA) as a probable risk factor for severe COVID-19 disease due to shared pathophysiological pathways. ${ }^{2,3} \mathrm{~A}$ retrospective study which was based on electronic health record has identified OSA as risk factor for mortality in COVID19 ARDS. ${ }^{4}$

Moreover the relationship of severity of OSA with that of COVID-19 has not been precisely documented.

This study was done to find prevalence of OSA in patients with COVID19 related moderate to severe Acute respiratory distress syndrome.

\section{METHODOLOGY}

This is a single centred prospective study conducted at a tertiary care teaching hospital in India. This study was carried over a period of two months (October 2020 to December 2020) on consecutive symptomatic COVID19 related acute respiratory distress syndrome patients who were discharged from ICU or isolation wards.

Aim of this study was to find prevalence of OSA in patients with COVID19 related Acute respiratory distress syndrome.

Inclusion Criteria: Patient meeting all the criteria were included:

1. Age $\geq 18$ years. 
2. Patients positive for COVID 19 by RT PCR of nasopharyngeal and oropharyngeal swabs at the time of ICU admission

3. Patients with $P / F<200$ and fulfils criteria of ARDS.

4. Patients must not require oxygen support at time of sleep study.

5. Patients must have tested negative COVID 19 (nasopharyngeal swab-RT PCR) at least 3 weeks prior to study

Exclusion criteria:

1. Patients who refused to give consent for PSG and participation in study

2. Patients who were not able to sit and stand without support even after 3 weeks of discharge.

3. Patients who required oxygen support after 3 weeks of discharge from ICU.

4. Any symptoms of active pulmonary infection.

All consecutive patients who were getting discharged from ICU were screened for general condition, maximum oxygen requirement during hospital course and interface of oxygen supplementation were noted. Appointment for polysomnography was allotted after 3 weeks of negative nasopharyngeal and oropharyngeal COVID19 RT PCR report.

On the day of PSG, they were again screened for any symptoms suggestive of respiratory infection, fever, throat pain, dyspnea and oxygen requirement prior to sleep study appointment. Patients were enrolled when found fit for study as per inclusion criteria. All demographic parameters, co morbidities, anthropometric parameters, STOP BANG, NoSAS, Berlin questionnaire (BQ) and Epworth Sleepiness Scores (ESS) were recorded prior to study. Questions for 
OSA and sleep disorders were filled for the period before subjects acquired COVID19.

From ICU records, weight of patient on ICU admission was noted. Weight was again taken on the day of PSG. Weight loss or gain from time of ICU admission was noted for each patient.

Precautions taken during Polysomnography: Following precautions were taken during PSG in all patients to prevent spread of infection among patients and staff:

1. No relatives were allowed to sleep in sleep lab room. Only patient was admitted in sleep lab.

2. Every patient was again checked for temperature, COVID-19 symptoms by sleep technician on day of sleep study.

3. Team of sleep technicians were assigned as per rotation protocol. Technicians had to wear personal protective equipment as per hospital protocol which included disposable eye cover, N-95 respirator, face shield, gown, gloves and shoe covers.

4. Disposable bed covers were used which were discarded after each study.

5. Each sleep room was properly sanitized as per hospital protocol. After PSG, room was fumigated and locked for 72 hours for safety purposes.

6. Level I PSG equipment were sanitized after every sleep study and were not used for next 72 hours.

Polysomnography (PSG)- All patients underwent level I PSG (Philips Respironics Alice 6). The following parameters were monitored during PSG: Electroencephalogram (EEG): frontal, central and occipital, electro-oculogram (EOG), sub-mentalis Electromyogram (EMG), nasal 
and oral airflow, anterior tibialis EMG, body position and electrocardiogram. Additionally, thoracic and abdominal movements were recorded by inductance plethysmography (zRIP). Oxygen saturation (SpO2) was monitored using a pulse oximeter. The tracing was scored using 30 second epochs. Scoring of events was done according to AASM scoring manual version $2012 .{ }^{5}$ Apneas were marked when there is drop in peak signal excursion by $\geq 90 \%$ of pre event baseline with duration of the $\geq 90 \%$ drop in sensor signal $\geq 10$ seconds. Hypopneas were scored if peak signal excursions drop by $\geq 30 \%$ of pre event baseline with duration of the $\geq 30 \%$ drop in signal excursion was $\geq$ 10 seconds with associated $\geq 3 \%$ oxygen desaturation from pre event baseline or event was associated with an arousal. The severity of obstructive sleep apnea was described by number of apneas and hypopneas per hour of sleep (apnea-hypopnea index [AHI]). OSA was defined as an $\mathrm{AHI} \geq 5$. OSA into three categories on the basis of $\mathrm{AHI}$ : mild (5-14.9) to moderate ( $\mathrm{AHI} 15-29.9)$ and severe $(A H I \geq 30)$.

Ethics review: Approval for ethics approval was taken approval from AlIMS Bhopal Institutional Human Ethics committee (IHECLOP/2020/IM309). Patients were counselled regarding purpose of the study and consent was taken from every patient.

Data analysis: Data analysis was done using $R$ software ${ }^{6}$ and gtsummary ${ }^{7}$ packages. We have summarized nominal variables with count and percentage and numerical variables with mean and its standard deviation. We have stratified our data across those who required oxygen and those who required ventilatory support (NIV/HFNC/IMV) . Then we have tested difference in distribution of numerical and categorical variables across these groups by using t-test 
and Chi-square test respectively. p-value less than 0.05 was considered as statistically significant.

Results: Consecutive patients of COVID ARDS admitted in ICU were recruited after 3-4 weeks of discharge. Out of 103 patients discharged during study period (October 2020 to 15 December 2020), 67 patients (46 male, 21 female) underwent Level I PSG.(Figure 1)

Mean Age was $52.6 \pm 10.9$ years and mean BMl at time of PSG was $27.5 \pm 6.2 \mathrm{Kg} / \mathrm{m}^{2}$. (Table 1) Seventeen out of sixty seven had $\mathrm{BMI} \geq 30$ $\mathrm{Kg} / \mathrm{m}^{2}$ and 50 had $\mathrm{BMl}<30 \mathrm{Kg} / \mathrm{m}^{2}$.

Median weight loss of patients was $0.0 \mathrm{Kg}$ (IQR 0.0-4.2) from time of ICU admission and PSG. Six patients had weight gain and 29 had weight loss; rest 32 patients had constant weight (i.e.less than $1 \mathrm{~kg}$ weight difference) between these two timelines.

Twenty two patients required oxygen varying from 5 LPM to 15 LPM during their ICU stay and did not require either Non Invasive Ventilation(NIV) or Invasive Mechanical Ventilation (IMV). Thirty two patients could be successfully managed with either NIV(20) or High Flow Nasal Canula (12) during ICU stay and 13 patients had required IMV. History of Diabetes Mellitus (DM) and hypertension was present in 40 patients each.

PSG characteristics (Table 2): Total sleep time was 343.2 \pm 86 minutes. Sleep efficiency was $75.9 \pm 14.2 \%$. Mean time (\%) during N1, N2, N3 and Rapid Eye movement (REM) was 15.9\%, 58.7\%, 8.5\% and 19\% percentage respectively. Mean $\mathrm{AHI}$ was $29.1 \pm 21.9$ per hour and arousal index was $23.9 \pm 13.3$

OSA (defined by $\mathrm{AHI} \geq 5$ ) was seen in 65/67 patients and 49 patients had moderate to severe OSA (i.e. AHI was more than 15). 
Discussion: This study shows that OSA is highly prevalent in patients with COVID19 induced ARDS. To the best of our knowledge, it is first study in which level I PSG was done in COVID19 survivors.

Breathing disruption seen in OSA is associated with sympathetic activity surge and hypoxemia which predisposes patients to cardiovascular and neurological complications. ${ }^{8,9,10}$ OSA has been associated with obesity, hypertension, Diabetes Mellitus (DM), Coronary artery disease, arrythmia, nocturia, chronic kidney disease, dyslipidaemia, metabolic syndrome, and pulmonary embolism. . $^{811,12}$ Association of COVID 19 ARDS is now known with various risk factors like obesity, older age, male sex, DM, hypertension, Coronary Artery Disease and Chronic Kidney Disease. ${ }^{13}$ Most important of these factors were age, obesity, and DM; all these three factors are closely interlinked with OSA. SARS CoV2 enters cells through Angiotensin Converting Enzyme-2 receptors in lungs and there is increased expression of these receptors in obese individuals. ${ }^{14}$

OSA might precipitate inflammation caused due to COVID19 by multiple pathways: OSA itself leads to hypoxemia and hypoventilation during sleep and superimposed COVID19 can lead to profound hypoxemia. ${ }^{15}$ Studies have shown increased inflammatory markers (like IL6 and CRP) in patients with OSA. ${ }^{16,17}$ OSA is a known risk factor for cardiac complications (hypertension, heart failure, acute cardiovascular events \& arrhythmias) and thus may increase cardiac morbidity and mortality in patients when they contract COVID infection. 8,11,12 DVT and PE risks were shown to be 3.50- and 3.97-fold higher respectively in OSA cohort than in the reference cohort. ${ }^{18}$ Hemodynamic alterations in OSA lead to 
polycythaemia and sluggish blood flow, which can possibly lead to procoagulant state. ${ }^{19,20,21}$ This hypercoagulable state can probably further increase risk for COVID related coagulopathy.

Recently few studies have tried to find out possibility of poor outcome in COVID19 with pre-existing OSA. In an electronic health record review, mortality was found to be much higher in patients with known OSA $(11.7 \%)$ compared to controls $(6.9 \%)$ with an odds ratio of $1.7923 .{ }^{4}$ In the CORONADO study, 144/1189 patients were already known case of OSA and presence of OSA was associated with poor outcome in COVID 19 related illness. ${ }^{22}$ In our previous study involving 213 patients, screening questionnaires for OSA \{STOPBANG, Berlin Questionnaire (BQ), NoSAS\} were more likely to be positive in patients who died compared to patients who survived. ${ }^{23}$ Proportion of patients who were classified as high risk for OSA by various OSA screening tools significantly increased with increasing respiratory support $(p<0.001$ for STOPBANG, BQ, ESS and $p=0.004$ for NoSAS). On binary logistic regression analysis, only two factors: age $\geq 55$ and STOPBANG score $\geq 5$ (correlating with moderate-severe OSA) were found to independent effect on mortality.

In all previous done work, association with severity of COVID19 was tried to be found in already known patients of OSA. But it is a known fact that more than $90 \%$ of patients with OSA remain undiagnosed. ${ }^{24}$ None of patients (in current study) were ever evaluated for OSA before COVID19 infection and yet $73 \%$ of them had moderate-severe OSA.

In pre-COVID19 era, very few studies were done to evaluate sleep disorders (with level I PSG) in ARDS survivors. In a study done from 
India, PSG was done in 20 ARDS survivors after 4 weeks of discharge from ICU: 2 had Central Sleep Apnea and one had OSA. ${ }^{25}$ In another study from United Kingdom, level I PSG was done immediately after discharge from ICU; out of 15 mechanically ventilated patients, 11 had OSA (AHI $\geq 5)$ and 9 (60\%) had Moderate-severe OSA (AHI $\geq 15) .{ }^{26} \mathrm{In}$ another study, seven ARDS survivors without previous sleep complaints reported difficulty sleeping 6 months after discharge from hospital. ${ }^{27}$ All these seven patients underwent PSG and only one had apnea. Further, N3 and REM sleep was significantly reduced, which was consistent with previous reports.

The high prevalence of OSA seen in patients with COVID19 ARDS in our study hints that OSA might be an independent risk factor for poor prognosis in patients with COVID19. To prove this however, PSG should be done in asymptomatic or minimally symptomatic individuals diagnosed with COVID19.

Untreated OSA can lead to cardiac complications and persistent symptoms including fatigability, insomnia, which are commonly seen in followup of COVID 19 patients. ${ }^{28}$ So in our opinion OSA should be ruled out in COVID19 ARDS survivors with these complaints and if moderatesevere OSA is present, it should be treated with Continuous Positive Airway Pressure (CPAP) therapy. ${ }^{29,30}$

Most important strength of this study is that gold standard level I PSG was done in consecutive ICU survivors. To the best of our knowledge, this is the first study in which PSG was done in COVID19 patients.

Important limitations of this study were:1) Presence of OSA could not be determined in patients who died during hospitalisation. This may have 
resulted in underestimation of prevalence of moderate to severe OSA. Although our previous work have shown increased mortality among those with high risk for OSA (as assessed with OSA screening questionnaires). ${ }^{23}$

2) Association between presence of OSA and severity of COVID19 could not be explored owing to inclusion of participants from only ICU. For this, patients with minimal or mild symptoms of COVID19 should have been included in study. However due to resource constraints, we restricted our study to ICU survivors. Participants of this study were patients from ICU only therefore findings should not be generalised to all COVID19 patients.

To summarise, moderate-severe OSA is highly prevalent (73\%) in COVID19 moderate to severe ARDS survivors and it will be interesting to explore further effect of role of OSA in pathophysiology of COVID19 ARDS.

\section{Acknowledgements:}

We want to thank Mr Amit Sen, Mr Chetan, Mr Ranjit and Ms Artee for performing polysomnography.

\section{Author Contribution:}

AG: Conceptualized, data collection, analysis, patient management and manuscript writing.

KS: Data collection, Patient management, manuscript writing

Av K: Patient management, Data collection, manuscript writing AK: Patient management, Manuscript writing

PKB: Data collection, manuscript writing CSKRS: Data collection, manuscript writing AP: Analysis, manuscript writing

Compliance with Ethical Standards: This is a retrospective analysis study and waiver of this study was taken from ethical clearance committee. 


\section{Disclosure of potential conflict of interest:}

AG: no financial support or conflict of interest

KS: no financial support or conflict of interest

Av K: no financial support or conflict of interest

AK: no financial support or conflict of interest

PKB: no financial support or conflict of interest

CSKRS: no financial support or conflict of interest

AP: no financial support or conflict of interest

Ethical approval: All procedures performed in studies involving human participants were in accordance with the ethical standards of the institutional and/or national research committee and with the 1964 Helsinki declaration and its later amendments or comparable ethical standards.

Informed consent: Informed consent was obtained from all individual participants included in the study.

Funding :This study received no funding. 


\section{References:}

1. Chen R, Liang W, Jiang M, Guan W, Zhan C, Wang T, et al. Risk Factors of Fatal Outcome in Hospitalized Subjects With Coronavirus Disease 2019 From a Nationwide Analysis in China. CHEST. 2020 Jul 1;158(1):97-105.

2. McSharry D, Lam MT, Malhotra A. OSA as a probable risk factor for severe COVID-19. Journal of Clinical Sleep Medicine. 2020 Sep 15;16(9):1649-1649.

3. Saxena K, Kar A, Goyal A. COVID 19 and OSA: exploring multiple cross-ways. Sleep Medicine. 2020 Nov 11;

4. Cade BE, Dashti HS, Hassan SM, Redline S, Karlson EW. Sleep Apnea and COVID-19 Mortality and Hospitalization. Vol. 202, American journal of respiratory and critical care medicine. NLM (Medline); 2020. p. 1462-4.

5. Berry RB, Budhiraja R, Gottlieb DJ, Gozal D, Iber C, Kapur VK, et al. Rules for scoring respiratory events in sleep: update of the 2007 AASM Manual for the Scoring of Sleep and Associated Events. Deliberations of the Sleep Apnea Definitions Task Force of the American Academy of Sleep Medicine. J Clin Sleep Med. 2012 Oct 15;8(5):597-619.

6. R Core Team. R: A Language and Environment for Statistical Computing [Internet]. Vienna, Austria: R Foundation for Statistical Computing; 2019. Available from: https://www.R-project.org/

7. Sjoberg DD, Curry M, Hannum M, Whiting K, Zabor EC, Drill E, et al. gtsummary: Presentation-Ready Data Summary and Analytic Result Tables [Internet]. 2020 [cited 2020 Oct 17]. Available from: https://CRAN.R-project.org/package=gtsummary

8. Coughlin SR, Mawdsley L, Mugarza JA, Wilding JPH, Calverley PMA. Cardiovascular and metabolic effects of CPAP in obese males with OSA. Eur Respir J.

9. Goyal A, Pakhare AP, Bhatt GC, Choudhary B, Patil R. Association of pediatric obstructive sleep apnea with poor academic performance: A school-based study from India. Lung India. 2018 Apr;35(2):132-6. 
medRxiv preprint doi: https://doi.org/10.1101/2021.05.04.21256593; this version posted May 6, 2021. The copyright holder for this preprint (which was not certified by peer review) is the author/funder, who has granted medRxiv a license to display the preprint in perpetuity. It is made available under a CC-BY-NC-ND 4.0 International license .

10. Choudhary B, Patil R, Bhatt GC, Pakhare AP, Goyal A, P A, et al. Association of Sleep Disordered Breathing with Mono-Symptomatic Nocturnal Enuresis: A Study among School Children of Central India. PLoS ONE. 2016;11(5):e0155808.

11. Goyal A, Pakhare A, Chaudhary P. Nocturic obstructive sleep apnea as a clinical phenotype of severe disease. Lung India. 2019 Feb;36(1):20-7.

12. Chaudhary P, Goyal A, Goel SK, Kumar A, Chaudhary S, Kirti Keshri S, et al. Women with OSA have higher chances of having metabolic syndrome than men: effect of gender on syndrome $Z$ in cross sectional study. Sleep Medicine. 2021 Mar 1;79:83-7.

13. Coperchini F, Chiovato L, Croce L, Magri F, Rotondi M. The cytokine storm in COVID-19: An overview of the involvement of the chemokine/chemokine-receptor system. Cytokine \& Growth Factor Reviews. 2020 Jun 1;53:25-32.

14. Iannelli A, Favre G, Frey S, Esnault V, Gugenheim J, Bouam S, et al. Obesity and COVID-19: ACE 2, the Missing Tile. Obesity Surgery. : 1 .

15. Goyal A, Pakhare A, Tiwari IR, Khurana A, Chaudhary P. Diagnosing obstructive sleep apnea patients with isolated nocturnal hypoventilation and defining obesity hypoventilation syndrome using new European Respiratory Society classification criteria: an Indian perspective. Sleep Medicine. 2020 Feb 1;66:85-91.

16. Shamsuzzaman ASM, Winnicki M, Lanfranchi $P$, Wolk R, Kara T, Accurso V, et al. Elevated C-reactive protein in patients with obstructive sleep apnea. Circulation. 2002 May 28;105(21):2462-4.

17. Motamedi V, Kanefsky R, Matsangas P, Mithani S, Jeromin A, Brock MS, et al. Elevated tau and interleukin- 6 concentrations in adults with obstructive sleep apnea. Sleep Med. 2018 Mar;43:71-6.

18. Peng Y-H, Liao W-C, Chung W-S, Muo C-H, Chu C-C, Liu C-J, et al. Association between obstructive sleep apnea and deep vein thrombosis / pulmonary embolism: a population-based retrospective cohort study. Thromb Res. 2014 Aug;134(2):340-5.

19. Choi JB, Loredo JS, Norman D, Mills PJ, Ancoli-Israel S, Ziegler $M G$, et al. Does obstructive sleep apnea increase hematocrit? Sleep Breath. 2006 Sep;10(3):155-60. 
medRxiv preprint doi: https://doi.org/10.1101/2021.05.04.21256593; this version posted May 6, 2021. The copyright holder for this preprint (which was not certified by peer review) is the author/funder, who has granted medRxiv a license to display the preprint in perpetuity. It is made available under a CC-BY-NC-ND 4.0 International license .

20. Solmaz S, Duksal F, Ganidağlı S. Is obstructive sleep apnoea syndrome really one of the causes of secondary polycythaemia? Hematology. 2015 Mar;20(2):108-11.

21. Goyal A, Saigal S, Niwariya Y, Sharma J, Singh P. Successful use of tPA for thrombolysis in COVID related ARDS: a case series. $J$ Thromb Thrombolysis [Internet]. 2020 Jul 2 [cited 2020 Jul 8]; Available from: https://doi.org/10.1007/s11239-020-02208-2

22. Cariou B, Hadjadj S, Wargny M, Pichelin M, AI-Salameh A, Allix I, et al. Phenotypic characteristics and prognosis of inpatients with COVID-19 and diabetes: the CORONADO study. Diabetologia. 2020 Aug 1;63(8):1500-15.

23. Kar A, Saxena K, Goyal A, Pakhare A, Khurana A, Saigal S. Association of Obstructive Sleep Apnea and severity of COVID-19: A hospital based observational study. medRxiv. 2020 Nov 13;2020.11.12.20230631.

24. Peppard PE, Young T, Barnet JH, Palta M, Hagen EW, Hla KM. Increased Prevalence of Sleep-Disordered Breathing in Adults. Am J Epidemiol. 2013 May 1;177(9):1006-14.

25. Dhooria S, Sehgal IS, Agrawal AK, Agarwal R, Aggarwal AN, Behera D. Sleep after critical illness: Study of survivors of acute respiratory distress syndrome and systematic review of literature. Indian J Crit Care Med. 2016 Jun;20(6):323-31.

26. A C, Am B, Re B, B F, Ad G, Sv B. Sleep-related breathing disorders following discharge from intensive care. Intensive Care Med. 2000 Apr 1;26(4):426-33.

27. Lee CM, Herridge MS, Gabor JY, Tansey CM, Matte A, Hanly PJ. Chronic sleep disorders in survivors of the acute respiratory distress syndrome. Intensive Care Med. 2009 Feb;35(2):314.

28. Hurley D. Sleep Neurologists Call It 'COVID-Somnia'-Increased Sleep Disturbances Linked to the Pandemic. Neurology Today. 2020 Jul 9;20(13):1.

29. Kushida CA; Chediak A; Berry RB; Brown LK; Gozal D; Iber C; Parthasarathy S; Quan SF; Rowley JA; Clinical Guidelines for the Manual Titration of Positive Airway Pressure in Patients with Obstructive Sleep Apnea. Journal of Clinical Sleep Medicine. 2008 Apr 15;04(02):157-71. 
30. Goyal A, Pakhare A, Subhedar R, Khurana A, Chaudhary P. Combination of positional therapy with positive airway pressure for titration in patients with difficult to treat obstructive sleep apnea. Sleep Breath [Internet]. 2021 Jan 23 [cited 2021 Jan 25]; Available from: https://doi.org/10.1007/s11325-021-02291-6

\section{Figure Legends:}

Figure 1: Flow chart of enrolment of patients for current study 
OSA COVID Analysis (PSG)

Table-1 Baseline demographic and clinical characteristics

\begin{tabular}{|c|c|c|c|c|}
\hline Characteristic & $\begin{array}{c}\text { Overall, } \mathrm{N}= \\
67^{1}\end{array}$ & $\begin{array}{c}\text { Oxygen, } \mathrm{N}= \\
22^{1}\end{array}$ & $\begin{array}{l}\text { NIV/HFNC/ } \\
\text { IMV, N }=45^{1}\end{array}$ & $\begin{array}{c}\mathrm{p}- \\
\text { value }^{2}\end{array}$ \\
\hline Age & $52.6(10.9)$ & $54.4(11.0)$ & $51.7(10.8)$ & 0.378 \\
\hline Men & $46(69 \%)$ & $17(77 \%)$ & $29(64 \%)$ & \multirow{2}{*}{0.434} \\
\hline Women & $21(31 \%)$ & $5(23 \%)$ & $16(36 \%)$ & \\
\hline Diabetes mellitus & $40(60 \%)$ & $15(68 \%)$ & 25 (56\%) & 0.469 \\
\hline $\begin{array}{l}\text { Hypertension } \\
\text { Coronary artery } \\
\text { disease }\end{array}$ & $\begin{array}{l}40(60 \%) \\
6(9.0 \%)\end{array}$ & $\begin{array}{c}12(55 \%) \\
0(0 \%)\end{array}$ & $\begin{array}{l}28(62 \%) \\
6(13 \%)\end{array}$ & $\begin{array}{l}0.737 \\
0.167\end{array}$ \\
\hline Body mass index & $27.5(6.2)$ & $28.1(5.7)$ & $27.2(6.5)$ & 0.404 \\
\hline $\begin{array}{l}\text { Waist } \\
\text { Circumference }\end{array}$ & $101.8(15.7)$ & $102.5(10.0)$ & $101.5(18.0)$ & 0.979 \\
\hline Hip Circumference & $105.0(13.4)$ & $104.2(10.9)$ & $105.4(14.6)$ & 0.973 \\
\hline $\begin{array}{l}\text { Neck } \\
\text { Circumference }\end{array}$ & $38.6(6.0)$ & $39.7(3.0)$ & $38.1(7.0)$ & 0.244 \\
\hline \multicolumn{5}{|l|}{ NOSAS Category } \\
\hline High Risk & $44(66 \%)$ & $16(73 \%)$ & $28(62 \%)$ & \multirow{2}{*}{0.564} \\
\hline Low Risk & $23(34 \%)$ & $6(27 \%)$ & $17(38 \%)$ & \\
\hline \multicolumn{5}{|l|}{$\begin{array}{l}\text { STOPBANG } \\
\text { Category }\end{array}$} \\
\hline High Risk & $17(25 \%)$ & $5(23 \%)$ & $12(27 \%)$ & 0.961 \\
\hline
\end{tabular}




\begin{tabular}{|c|c|c|c|c|}
\hline Characteristic & $\begin{array}{c}\text { Overall, } \mathrm{N}= \\
67^{1}\end{array}$ & $\begin{array}{c}\text { Oxygen, } \mathrm{N}= \\
22^{1}\end{array}$ & $\begin{array}{l}\text { NIV/HFNC/ } \\
\text { IMV, N }=45^{1}\end{array}$ & $\begin{array}{c}\mathrm{p}- \\
\text { value }^{2}\end{array}$ \\
\hline Low Risk & $50(75 \%)$ & 17 (77\%) & $33(73 \%)$ & \\
\hline \multicolumn{5}{|l|}{ Berlin } \\
\hline High Risk & $40(60 \%)$ & $13(59 \%)$ & $27(60 \%)$ & \multirow{2}{*}{$>0.999$} \\
\hline Low Risk & $27(40 \%)$ & $9(41 \%)$ & $18(40 \%)$ & \\
\hline \multicolumn{5}{|c|}{${ }^{1}$ Statistics presented: Mean (SD); n (\%) } \\
\hline \multicolumn{5}{|c|}{$\begin{array}{l}\text { 2Statistical tests performed: Wilcoxon rank-sum test; Fisher's exact test; chi-square test of } \\
\text { independence } \\
\text { NIV: Non Invasive Ventilation; IMV: Invasive Mechanical Vemtilation; HFNC: High Flow Nasal } \\
\text { Canula }\end{array}$} \\
\hline
\end{tabular}

\section{Table-2 Distribution of PSG variables}

\begin{tabular}{|l|c|c|c|c|}
\hline Characteristic & Overall, $\mathrm{n}=67^{1}$ & Oxygen, $\mathrm{n}=22^{1}$ & $\mathrm{NIV} / \mathrm{IMV}, \mathrm{n}=45^{1}$ & $\mathrm{p}$-value \\
\hline Total sleep time (in minutes) & $343.2(86.0)$ & $358.5(53.3)$ & $335.7(97.8)$ & 0.580 \\
Sleep efficiency (\%) & $75.9(14.2)$ & $78.3(8.4)$ & $74.7(16.2)$ & 0.873 \\
\hline Sleep latency (in minutes) & $19.8(22.0)$ & $17.3(21.4)$ & $21.1(22.5)$ & 0.378 \\
\hline N1 in percentage & $15.9(10.1)$ & $11.9(4.5)$ & $17.9(11.4)$ & 0.031 \\
\hline N2 in percentage & $58.7(12.4)$ & $60.4(10.7)$ & $57.9(13.2)$ & 0.522 \\
\hline N3 in percentage & $8.5(7.6)$ & $10.5(9.3)$ & $7.6(6.5)$ & 0.268 \\
\hline REM in percentage & $19.0(14.8)$ & $19.0(8.4)$ & $19.0(17.2)$ & 0.419 \\
\hline AHI (Apnea Hypopnea Index) & $29.1(21.9)$ & $24.9(20.2)$ & $31.1(22.6)$ & 0.175 \\
\hline NREM AHI & $28.2(22.9)$ & $23.1(19.8)$ & $30.7(24.1)$ & 0.184 \\
\hline REM AHI & $31.2(25.0)$ & $26.3(22.4)$ & $33.7(26.1)$ & 0.207 \\
\hline OSA severity & $2(3.0 \%)$ & $1(4.5 \%)$ & $1(2.2 \%)$ & 0.395 \\
\hline No OSA & & & & \\
\hline
\end{tabular}


medRxiv preprint doi: https://doi.org/10.1101/2021.05.04.21256593; this version posted May 6, 2021. The copyright holder for this preprint (which was not certified by peer review) is the author/funder, who has granted medRxiv a license to display the preprint in perpetuity. It is made available under a CC-BY-NC-ND 4.0 International license .

\begin{tabular}{|c|c|c|c|c|}
\hline Characteristic & Overall, $\mathrm{n}=67^{1}$ & Oxygen, $n=22^{1}$ & $\mathrm{NIV} / \mathrm{IMV}, \mathrm{n}=45^{1}$ & $p$-value ${ }^{2}$ \\
\hline Mild & $16(24 \%)$ & $6(27 \%)$ & $10(22 \%)$ & \\
\hline Moderate & 25 (37\%) & $10(45 \%)$ & $15(33 \%)$ & \\
\hline Severe & 24 (36\%) & $5(23 \%)$ & $19(42 \%)$ & \\
\hline Positional OSA & 33 (49\%) & $12(55 \%)$ & 21 (47\%) & 0.730 \\
\hline NREM Predominant & 13 (19\%) & $3(14 \%)$ & $10(22 \%)$ & \multirow{2}{*}{0.765} \\
\hline REM Predominant & $14(21 \%)$ & $5(23 \%)$ & $9(20 \%)$ & \\
\hline Arousal index & $23.9(13.3)$ & $23.2(13.7)$ & $24.3(13.2)$ & 0.694 \\
\hline ODI & $22.8(26.9)$ & $15.3(17.6)$ & $26.5(30.0)$ & 0.055 \\
\hline T90 & $6.0(17.4)$ & $0.6(1.3)$ & $8.7(20.7)$ & 0.049 \\
\hline Weight loss (in Kg) & $3.1(5.5)$ & $2.4(4.7)$ & $3.5(5.8)$ & 0.654 \\
\hline \multicolumn{5}{|c|}{${ }^{1}$ Statistics presented: Mean (SD); n (\%) } \\
\hline \multicolumn{5}{|c|}{$\begin{array}{l}{ }^{2} \text { Statistical tests performed: Wilcoxon rank-sum test; Fisher's exact test; chi-square test of } \\
\text { independence }\end{array}$} \\
\hline \multicolumn{5}{|c|}{$\begin{array}{l}\text { AHI: Apnea Hypopnea Index; NREM: Non-Rapid Eye Movement; ODI: Oxygen Desaturation } \\
\text { Index; OSA: Obstructive Sleep Apnea; REM: Rapid Eye Movement; T90: Percentage sleep time } \\
\text { spent with spO2<90\% }\end{array}$} \\
\hline
\end{tabular}




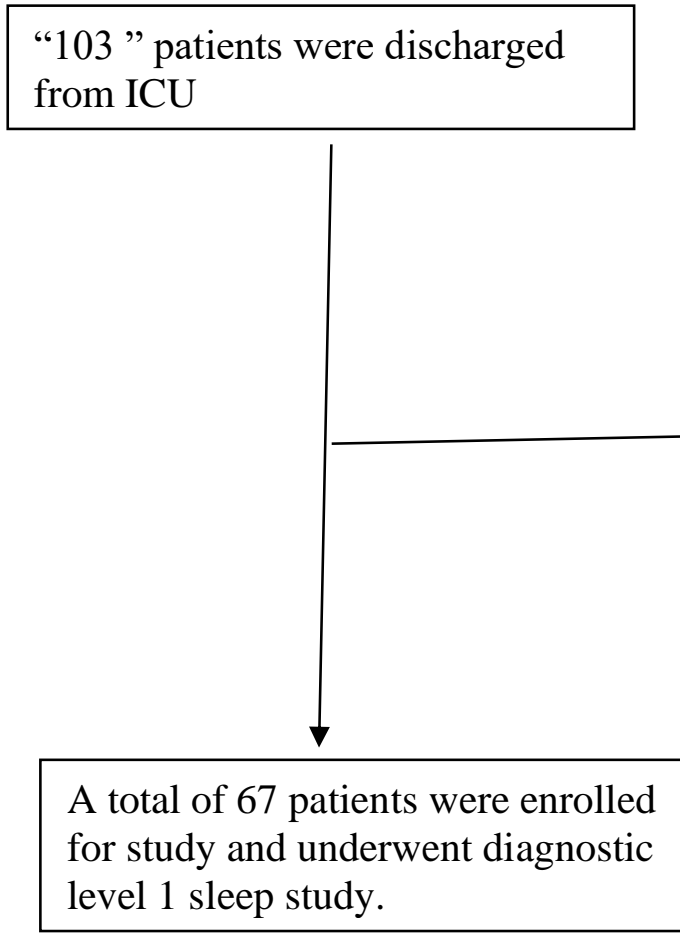

1. "19" patients refused for participation

2. 2 patients required oxygen support at time of sleep study

3. 5 patients were unable to sit or stand without support.

4. 10 Patients lost to follow up.

Figure 1: Flow chart of enrolment of patients for current study 